\title{
Rose Bertin, ministre des modes de Marie-
} Antoinette

Jacques Bernet

\section{Q OpenEdition \\ 1 Journals}

Édition électronique

URL : https://journals.openedition.org/ahrf/2015

DOI : 10.4000/ahrf.2015

ISSN : 1952-403X

\section{Éditeur :}

Armand Colin, Société des études robespierristes

\section{Édition imprimée}

Date de publication : 1 juin 2005

Pagination : 180-181

ISSN : 0003-4436

\section{Référence électronique}

Jacques Bernet, «Rose Bertin, ministre des modes de Marie-Antoinette », Annales historiques de la Révolution française [En ligne], 340 | avril-juin 2005, mis en ligne le 20 avril 2006, consulté le 23 avril 2022. URL : http://journals.openedition.org/ahrf/2015 ; DOI : https://doi.org/10.4000/ahrf.2015

Ce document a été généré automatiquement le 23 avril 2022.

Tous droits réservés 


\title{
Rose Bertin, ministre des modes de Marie-Antoinette
}

\author{
Jacques Bernet
}

\section{RÉFÉRENCE}

Michèle SAPORI, Rose Bertin, ministre des modes de Marie-Antoinette, Paris, Institut Français de la Mode et Éd. du Regard (distribution Seuil), 2003, 318 p., ISBN

2-914863-04-7, $19 €$.

1 «Rose» Bertin, la modiste d'origine picarde de Marie-Antoinette, mais aussi du tout Paris frivole et même du Gotha européen de la fin d'un XVIIIe siècle réputé français, avait déjà fait l'objet de recherches et d'honorables biographies au début du XXe siècle : Émile Anglade, Pierre de Nouvion et Jacques Doucet (1911) s'étaient intéressés avant tout à l'histoire de la mode et du vêtement, mais aussi à une personnalité majeure de l'entourage de la reine. Sans méconnaître ces aspects incontournables, Michèle Sapori reprend et élargit l'étude d'une femme hors du commun, à la lumière de nos préoccupations historiques contemporaines, en s'appuyant sur des sources variées et des méthodes d'investigation renouvelées: il s'agit ainsi de mieux comprendre l'itinéraire singulier, mais emblématique, d'une représentante du sexe «faible», de surcroît issue du peuple, devenue par ses propres talents une créatrice et une femme d'affaires, en un domaine promis à un grand avenir (d'ailleurs plutôt masculin), celui de la haute couture parisienne. L'intérêt du sujet tient autant à l'histoire de l'entreprise qu'à celle des femmes, dans un contexte historique spécifique et controversé, transition politique et sociale majeure entre l'Ancien Régime et notre monde contemporain. Comme le souligne l'auteur dans son introduction : «ce n'est pas par l'histoire de MarieAntoinette ou par l'histoire du costume que Melle Bertin nous revient, mais par d'autres chemins, ceux de l'histoire du négoce et de l'histoire culturelle».

2 L'ouvrage, divisé en trois grandes parties thématiques d'inégale longueur, présente tour à tour «le fond de commerce de Melle Bertin»; sa famille, ses relations et son 
ascension sociale; son destin pendant et après la rupture révolutionnaire, qui mit fin à la prospérité de son entreprise et la fit sortir de la «sphère des modes».

3 Riche et novatrice, la première partie replace fort bien le "Grand Mogol», magasin moderne de nouveautés situé près du Palais Royal, au cœur du monde parisien de la mode, dont l'essor coïncida avec le règne de Louis XVI et surtout de Marie-Antoinette. Avec trente ouvrières salariées, quelque cent vingt fournisseurs et de multiples soustraitants, c'était déjà une grosse affaire, au service d'une clientèle royale et aristocratique, prestigieuse et exigeante, souvent mauvaise payeuse, au point de mettre parfois en péril une entreprise à laquelle le public prêtait de fabuleux bénéfices au détriment notamment de l'État et des contribuables. L'auteur montre aussi l'ambiguïté des rapports entre la modiste roturière, d'une part, la reine, la Cour et la noblesse, d'autre part, "au cœur d'une communauté devenue un rouage du régime»: Melle Bertin, aurait été le mauvais génie de Marie-Antoinette, entretenant par intérêt ses frivoles dépenses et alimentant son impopularité, tandis qu'elle se montrait à la fois solidaire et rivale de sa clientèle nobiliaire, qui jalousait par ailleurs sa trop grande familiarité avec la souveraine. L'étude des stratégies commerciales, des pratiques financières, avec les réussites et les difficultés du monde de l'entreprise de luxe à la fin de l'Ancien Régime, fondée sur l'analyse des livres de comptes, des créances ou des correspondances, constitue un des apports les plus intéressants de l'ouvrage, qui brosse également un tableau original et circonstancié de la vie sociale et culturelle d'une grande capitale comme Paris à la fin du XVIIIe siècle.

4 Non moins documentée, la seconde partie présente les origines géographiques et sociales (modestes) du personnage, soulignant le poids du «creuset picard » et de sa tradition textile, avec lesquels la modiste parisienne ne rompit jamais complètement. On mesure d'autant mieux les qualités personnelles et la force de caractère de cette femme restée célibataire, qui réussit par ses seuls talents et son travail une spectaculaire ascension sociale, dont elle fit bénéficier l'ensemble de sa parentèle, en chef de famille avisé sachant parfaitement user de son autorité, de ses nombreuses relations et de son sens des affaires.

Certes, la Révolution vint sérieusement contrarier la belle entreprise et menacer une situation éminente devenue périlleuse. Mais la modiste sut faire front, poursuivre tant qu'elle le put ses activités, avec l'étranger et même la famille royale, spéculer sur la vente des biens nationaux, n'émigrant qu'au moment le plus critique de la période, pour revenir dès après Thermidor et tenter de sauver ce qui pouvait l'être. Elle ne retrouva pas son ancienne prospérité, mais récupéra ses biens, comme sa propriété d'Épinay, où elle mourut en 1813 à 66 ans, déjà entrée dans sa légende, noire et rose, dont ce passionnant livre, bien écrit, nous fournit toutes les clés. 